\title{
AGRONEGOCIO, CAMPESINOS, ESTADO Y GOBIERNOS DE IZQUIERDA EN AMÉRICA LATINA
}

\section{INTRODUCCIÓN Y REFLEXIONES TEÓRICAS}

\author{
Leandro Vergara-Camus y Cristóbal Kay
}

EL UMBRAL DEL MILENIO fue marcado por victorias electorales de partidos o políticos de izquierda apoyados por movimientos campesinos e indígenas en Venezuela (1998), Brasil (2003), Argentina (2003), Uruguay (2004), Bolivia (2005), Ecuador (2006), Nicaragua 2006), Paraguay (2008) y El Salvador (2009). En muchos de estos casos, fueron reelegidos varias veces antes de perder el poder en las urnas o ser derribados por las fuerzas conservadoras, como sucedió con el presidente Fernando Lugo en Paraguay en junio de 2012 y con la presidenta Dilma Rousseff en Brasil en agosto de 2016. Esta ola no tiene paralelo en ninguna otra región del llamado tercer mundo. Los movimientos campesinos en la mayoría de estos países han sido miembros activos de La Vía Campesina y han sido claves en el desarrollo de su ideología, su propuesta de alternativa, así como su forma organizativa y estrategia (Desmarais, 2007; Martínez-Torres y Rosset, 2010). Lo que los movimientos campesinos nacionales han logrado en cada uno de estos países suscita el interés de muchos activistas y estudiosos de las luchas agrarias en América latina y el resto del mundo. En la mayoría de los casos, ha pasado bastante tiempo para permitir una evaluación seria de las políticas agrarias que estos estados han implementado y cómo los movimientos han reaccionado. Varios excelentes estudios nacionales ya han sido publicados, algunos de los 
cuales son mencionados en este libro. Sin embargo, hasta ahora no ha habido un intento sistemático de evaluar comparativamente los logros, las limitaciones y las contradicciones de las políticas agrarias de los gobiernos de izquierda ${ }^{1}$.

En varios países latinoamericanos, los movimientos campesinos han estado a la vanguardia de la resistencia al neoliberalismo (Petras y Veltmeyer, 2003; Deere y Royce, 2009; Vergara-Camus, 2009 y 2013). Han sido importantes aliados de los partidos de izquierda, ayudándolos políticamente y electoralmente. En Brasil, el Movimiento de los Trabajadores Rurales Sin Tierra (MST) mantiene una larga alianza con el Partido de los Trabajadores (PT). En Bolivia, el movimiento cocalero fue liderado por Evo Morales y fue uno de los fundadores del Movimiento al Socialismo (MAS). También otros movimientos indígenas, movimientos sociales y sindicatos apoyaron y participaron en el MAS. En Ecuador, el movimiento indígena a través de varias de sus organizaciones, en particular la Confederación Nacional de Nacionalidades Indígenas del Ecuador (CONAIE) y la Federación Nacional de Organizaciones Campesinas, Indígenas y Negras (FENOCIN) jugaron un papel importante en el éxito electoral de Rafael Correa en 2005, aunque nunca se unieron a su partido, la Alianza PAIS. Tanto en Bolivia como en Ecuador, los movimientos campesinos e indígenas participaron activamente en la Asamblea Constituyente que adoptó la soberanía alimentaria y el Buen Vivir como principios rectores de las políticas estatales ${ }^{2}$. Finalmente, en Nicaragua, el regreso de los sandinistas al poder no fue acompañado por una movilización de movimiento campesino y popular, pero el Frente Sandinista de Liberación Nacional (FSLN) siguió manteniendo fuertes vínculos con los principales movimientos que representaban a los campesinos.

1 Existe una abundante literatura sobre el giro a la izquierda en América Latina que se inició con la victoria electoral de Hugo Chávez en Venezuela, véase Barrett et al. (2008), Castañeda y Morales (2008), Panizza (2009), Petras y Veltmeyer (2009), Cameron y Hershberg (2010), Weyland et al. (2010), Sader (2011), Webber y Carr (2013), Ellner (2014), entre otros. Sin embargo, casi ninguno de estos libros examina de manera detenida las dimensiones agrarias. El único libro que hace esto es el excelente libro publicado en castellano por Gascón y Montagut (2010).

2 La idea de Buen Vivir (Sumak Kawsay en Quechua, Sumak Qamaña en Aymara), basada en una conceptualización indígena y alternativa del bien estar, las relaciones humanas y las relaciones de los humanos con la naturaleza, ha emergido recientemente en los trabajos de intelectuales y académicos indígenas y no indígenas y se ha presentado como una crítica a la conceptualización occidental del desarrollo (Acosta, 2013a). Estamos conscientes que existe un debate en torno a estos conceptos y su sentido y contenido varían según el contexto. La influencia de este concepto sobre las políticas agrarias será analizada en este capítulo y en algunos de los capítulos de este libro. 
Los estudios compilados en este libro se centran en los países en los que han sido elegido partidos o coaliciones de izquierda, ampliamente definida, con el apoyo de (o en alianza con) movimientos campesinos independientes o después de muchos años de movilización de movimientos populares. Estos partidos o coaliciones de izquierda se presentaron con un claro discurso anti-neoliberal, prometiendo revertir algunas de las principales políticas neoliberales e implementar políticas a favor de las clases populares. Los casos que cumplen estos criterios son: Argentina, Bolivia, Brasil, Ecuador, Nicaragua, Uruguay y Venezuela, con Paraguay representando un caso de golpe reaccionario. Chile no cumple con estos criterios, ya que la crítica del neoliberalismo o un discurso de clase no han formado parte central de los programas de los gobiernos de la Concertación que fue una coalición de partidos de centro e izquierda.

\section{UNA APARENTE PARADOJA: DE LAS MOVILIZACIONES A LA PROPUESTA, DE LA PROPUESTA A LA RETÓRICA}

La mayoría de estos partidos o coaliciones gubernamentales habían prometido reformas sustanciales en las políticas agrarias, incluyendo una reforma agraria redistributiva y unas políticas de apoyo para los pequeños agricultores familiares, durante sus campañas electorales para llegar al gobierno. Sin embargo, nosotros argumentaremos que la mayoría de ellos no han tenido la capacidad o la voluntad de alterar el modelo de desarrollo rural heredado del proceso de mundialización neoliberal. Si bien la pobreza rural ha disminuido, sobre todo debido a los pagos de bonos y el aumento del salario mínimo por los gobiernos de izquierda, los niveles de desigualdad siguen siendo altos, aunque en algunos casos han disminuido ligeramente. Todos estos gobiernos, en diferente medida, han movilizado en sus discursos públicos las ideas de soberanía alimentaria o el Buen Vivir, pero muy pocas de sus políticas agrarias más importantes están orientadas a construir un nuevo modelo post-neoliberal de desarrollo rural. ¿Por qué ha sido así? ¿Cuáles han sido las diferentes respuestas del campesinado a este decepcionante resultado? En algunos países, sobre todo Ecuador y Brasil, los movimientos campesinos han sido muy críticos de estos nuevos gobiernos, y hasta se han enfrentado abiertamente con ellos, exigiéndoles políticas más alineadas con sus promesas originales. ¿Por qué no han podido los movimientos presionar a los gobiernos para que apliquen políticas más radicales? ¿Cómo se puede explicar esta última fase de la lucha de los movimientos campesinos latinoamericanos, ciertamente menos exitosa y mucho más difícil?

La respuesta no consiste en una simple cooptación de la agenda de los movimientos campesinos e indígenas por parte de políticos y 
gobiernos sin escrúpulos. Tampoco es un abandono total de los campesinos y trabajadores rurales por parte de los gobiernos de izquierda. La mayoría de estos gobiernos han implementado una variedad de políticas y encontrado fondos adicionales para ayudar a los pequeños productores familiares, y una importante cantidad de micro-proyectos llegan a las comunidades indígenas y campesinas (ver el capítulo de conclusión de este libro para un estudio comparativo de estas políticas). Algunas políticas intentan vincular a los pequeños productores familiares y campesinos con la agroindustria a través de incentivos fiscales y otras medidas indirectas, creyendo que existe espacio para que la gran producción capitalista y los pequeños productores pueden prosperar conjuntamente en la agricultura (Córdoba y Jansen, 2014). Se trata más bien de evaluar si estas políticas son suficientes para mejorar las condiciones de vida de los campesinos y los trabajadores rurales, fortalecer su capacidad organizativa y política, cumplir los objetivos de la soberanía alimentaria y del Buen Vivir, para poder así sentar las bases de una transformación radical del campo.

A la base de esta aparente paradoja se encuentra una contradicción: aunque la propuesta ideológica provenga de los movimientos sociales, alcanzar la soberanía alimentaria y el Buen Vivir requieren y dependen de la existencia de un Estado interventor (McKay et al., 2014). Sin embargo, el Estado desarrollista fue desmantelado por el neoliberalismo que promueve una concepción minimalista del Estado y la descentralización, estableciendo así nuevos marcos para la interacción de las políticas estatales con las organizaciones de la sociedad civil. Por lo tanto, es necesario reorganizar el Estado una vez más si se quieren alcanzar los objetivos de la soberanía alimentaria y el Buen Vivir (Clark, 2016). Incluso en los casos en que el Estado ha comenzado a recuperar algunas de sus capacidades institucionales, sus políticas no siempre se han orientado hacia el logro de estos objetivos (Henderson, 2016), e incluso han tomado formas asistencialistas o clientelistas muy arraigadas en la historia latinoamericana. Además, los movimientos sociales más vinculados a los objetivos de la soberanía alimentaria y el Buen Vivir no han sido capaces de tener una influencia real sobre el Estado. Por lo tanto, se vuelve esencial explorar las razones que explican esta aparente falta de capacidad de los movimientos sociales y la falta de voluntad o capacidad del Estado para tomar las medidas requeridas.

Esta contradicción requiere una explicación empírica y analítica, mediante el estudio de casos y la comparación de las políticas estatales, la relación entre los movimientos campesinos y el Estado, y entre el Estado y las clases dominantes nacionales y transnacionales. Sin embargo, también requiere una explicación teórica, a través de una perspectiva particular que se enfoque en las configuraciones de clase, 
la naturaleza del Estado y su papel dentro de la economía, así como su estrategia de desarrollo. ¿Por qué los gobiernos de izquierda no han sido capaces de desafiar más radicalmente el orden neoliberal? ¿La soberanía alimentaria y el Buen Vivir inspiran realmente las políticas de estos gobiernos o fueron simplemente instrumentalizados por los nuevos regímenes con fines electorales o de legitimación?

Empíricamente, el objetivo central de este libro es de evaluar hasta qué punto estos gobiernos han continuado apoyando la agricultura capitalista de gran escala y el agronegocio y hasta qué punto han apoyado la pequeña agricultura familiar y campesina y han mejorado las condiciones de los trabajadores rurales.

Una evaluación de la reconfiguración de clase que la reestructuración neoliberal del campo ha desencadenado en los diferentes países abarcados por los capítulos es nuestro punto de partida. Se prestará una atención particular al análisis sobre qué tipo de agricultura capitalista a gran escala y agronegocio se han ido beneficiando de esta reestructuración y también cómo las diferentes fracciones de clase dentro de campesinado se han visto afectadas y han reaccionado ante esta reestructuración. Partiendo de este punto de vista, los capítulos de este libro analizan las políticas de los gobiernos de izquierda, como la distribución de tierras, las subvenciones, los créditos y la creación de mercados han favorecido a ciertos grupos sociales del campo. Los capítulos también analizan las diferentes maneras como los productores campesinos se han integrado y subordinado al nuevo modelo controlado por el agronegocio y si algunos han sido capaces de crear un espacio propio dentro de este modelo. Uno de nuestros objetivos es determinar si los gobiernos de izquierda se ubican en continuidad o en ruptura con gobiernos anteriores.

Los capítulos de este libro abordan estas cuestiones centrales para cada país mencionado, mientras que esta introducción ofrece un marco teórico para comprender el significado histórico de estos cambios desde un enfoque crítico de economía política agraria, que enfatiza la centralidad del Estado en la agricultura. Esta introducción también ofrece una visión general de los amplios cambios que el neoliberalismo y el surgimiento del agronegocio en América Latina han desencadenado desde los años noventa para establecer qué tipo de campo heredaron los gobiernos de izquierda y cuales cambios a favor de las clases subalternas se esperaban de ellos.

\section{EL ESTADO, EL DESARROLLO CAPITALISTA DE LA AGRICULTURA Y LA FORMACIÓN DE CLASES EN AMÉRICA LATINA}

Desde nuestro punto de vista, una explicación del porqué los movimientos sociales fueron incapaces de influir en los gobiernos de iz- 
quierda para que implementaran políticas más radicales a favor de los pequeños productores y disminuyeran su apoyo a la agronegocio requiere de un marco teórico que adopte una perspectiva de clase en torno a la naturaleza y el rol del Estado. Henry Bernstein (2014: 1054) menciona que el Estado es un tema obvio pero que nadie quiere discutir el Estado (the elephant in the room) en el programa del movimiento por la soberanía alimentaria. Su observación es correcta, pero el Estado es también un tema obvio que todos ignoran en la más reciente ola de estudios agrarios. Muchos de los trabajos reciente sobre las transiciones agrarias o la cuestión agraria, el acaparamiento de tierras, el "acaparamiento verde" (green grabbing) y el auge del agronegocio han puesto de manifiesto el papel central que desempeña el Estado en los procesos de cambio agrario. Sin embargo, muy pocos estudios han intentado re-actualizar la forma en que entendemos el Estado o cuestionar las conceptualizaciones implícitas sobre la naturaleza del Estado que reproducen los estudiosos agrarios. Incluso son pocos los estudios que se dedican a teorizar la naturaleza actual del Estado en el campo o en relación a la agricultura. Por ejemplo, ninguno de los estudiosos que participaron en el libro sobre la nueva cuestión agraria editado por Akram-Lodhi y Kay (2009) se dedicó a desarrollar una conceptualización del Estado, a pesar de que el Estado se perfilaba como un actor central en los análisis de estos autores. De la misma manera, una gran parte de las evaluaciones de la capacidad de los movimientos rurales en América Latina se enfocó en las políticas estatales o las estrategias de los movimientos rurales hacia el Estado. Sin embargo, muy pocos estudiosos adoptan explícitamente una concepción particular del Estado o se refieren a las discusiones teóricas alrededor de la teoría del Estado. Solo unos pocos estudiosos (Wolford et al., 2013; Giarracca y Teubal, 2008) han intentado teorizar lo que es específico o peculiar acerca de la forma que el Estado adopta en el campo o el papel que juega en el conflicto social sobre los recursos. Debido a esta centralidad del Estado, consideramos que es necesario volver al Estado (una vez más), no solo temáticamente sino también a través de una discusión teórica sobre la naturaleza y el papel del Estado dentro de proceso de mundialización de la agricultura, así como su rol en el posible surgimiento de modelos alternativos de desarrollo.

Existe una gran diversidad dentro de los trabajos que se dedican a estudiar al Estado, pero si nos limitamos a la literatura sobre estudios agrarios y recursos naturales, estos se pueden organizar en cinco enfoques teóricos: el enfoque neo-weberiano, el enfoque schumpeteriano, el enfoque marxista, el enfoque un foucaultiano y el enfoque ecléctico. En la academia anglo-sajona, la perspectiva neo-weberiana es aquella que parte del supuesto que el Estado moderno se caracteriza 
por tener una autonomía relativa ante las clases sociales. Esta autonomía le permite tener una función desarrollista o depredadora (Evans, 1995; Karl, 1997, Minns, 2001; Perraton, 2005). De cierta manera, esta perspectiva es adoptada por los autores que hablan de un "retorno del Estado" como una de las características centrales de los gobiernos de izquierda en América Latina (Grugel y Riggirozzi, 2012; Enríquez y Newman, 2016, Clark, en este libro). Según esta perspectiva, lo que determina el carácter del Estado es la naturaleza de su burocracia y los tipos de vínculos entre la sociedad (principalmente el capital, pero también el trabajo) y el Estado. La perspectiva schumpeteriana parte de la fuente de ingresos del Estado para determinar el carácter del Estado. Para este enfoque, los países ricos en recursos tienden a producir Estados rentistas y sociedades en las cuales la mayoría de los individuos buscan tener acceso a la renta extractivista. Por ende, un Estado rentista, puesto que no se financia mediante los impuestos a una clase de empresarios innovadores que se espera en contra parte a ser tomada en cuanta en las decisiones del Estado, como acontecería en un Estado fiscal, desestimularía el empresariado y el desarrollo económico (Moore, 2004; Weyland, 2009). El enfoque marxista encuentra sus orígenes en varios teóricos del Marxismo clásico como Marx, Lenin, Trotsky, Gramsci y autores más recientes como Poulantzas, Miliband y Jessop. En la literatura anglosajona reciente, muchos han vuelto a las conceptualizaciones Poulantzasianas, como su conceptualización del Estado como gestor de los intereses a largo plazo del capital y la idea de la "internacionalización del Estado", que sugiere que los intereses transnacionales permean estructuralmente el aparato estatal nacional y determinan sus políticas (Poulantzas, 1978; Glassman, 1999; Brand y Görg, 2008; Wissen, 2009). El concepto del "Estado extendido" de Gramsci, que incluye a la sociedad política y a la sociedad civil, también ha sido recuperado por varios teóricos para analizar las formas en que las diferentes clases construyen y desafían el orden hegemónico neoliberal (Vergara-Camus, 2014, Lapegna, en este libro). La perspectiva foucaultiana se apoya en la idea de Michel Foucault de gubernamentalidad (Foucault, 2001) que sugiere que un poder de tipo estatal es de alguna manera interiorizado por todos los sujetos sociales que están involucrados con el Estado o la formulación de políticas gubernamentales (Escobar, 1995; Zibechi, 2010). Finalmente, un enfoque ecléctico, que combina varias de las ideas de los otros enfoques, ha sido propuesto por Wolford et al. (2013), quienes siguiendo a Bob Jessop (1990, 2007), conceptualizan al Estado como un espacio contradictorio de conflictos de intereses donde los actores despliegan sus estrategias en múltiples niveles. Las estrategias de los diferentes actores se encuentran formadas por una variedad de 
tácticas, como buscar ubicarse en posiciones estratégicas dentro del Estado, presionar a los actores ubicados en los diferentes niveles de estas posiciones estratégicas y utilizar discursos hegemónicos y contrahegemónicos para convencer o forzar a las autoridades políticas a tomar ciertas decisiones.

El propósito de este capítulo no nos permite explayarnos sobre las fortalezas, limitaciones y contradicciones particulares de estos diferentes enfoques, pero queremos señalar un dilema común que todas estas perspectivas comparten. Existe dentro de todas ellas una tensión entre la necesidad de producir una teoría general del Estado, que sea aplicable al desarrollo capitalista en general, o a los países en desarrollo, y la necesidad de desarrollar una metodología o un marco analítico que se adapte a la diversidad de casos, procesos y correlaciones de fuerzas entre las clases. El primer objetivo tiende a privilegiar las determinaciones estructurales para facilitar la generalización, mientras que el segundo objetivo tiende a reconocer una agencia mayor por parte de los diferentes actores dentro de la estructura del Estado y abre cauce para resultados contingentes. El desafío de esta contribución teórica de este libro es de encarar esta tensión desarrollando un marco que reconozca la naturaleza de clase y el papel del Estado en el desarrollo de la agricultura capitalista en los países latinoamericanos desde los albores del siglo veintiuno, al mismo tiempo que permita comprender este desarrollo como resultado de decisiones de las estrategias de las diferentes clases sociales y de la correlaciones de fuerza entre ellas. En la siguiente sección, presentamos este marco teórico que se construye en torno a las categorías como la propiedad políticamente constituida, la propiedad privada absoluta, la acumulación por desposesión, la reproducción ampliada del capital y la renta de suelo. Pensamos que la combinación de estas categorías proporciona un marco coherente para explicar las transformaciones agrarias desencadenadas por la globalización neoliberal.

\section{LA DISTINCIÓN ENTRE LA "PROPIEDAD POLÍTICA CONSTITUIDA" Y LA “PROPIEDAD PRIVADA ABSOLUTA", Y EL MERCADO “COMO OPORTUNIDAD” Y EL MERCADO “COMO IMPERATIVO”}

En su ahora famoso capítulo sobre la "acumulación primitiva" en el volumen I de El Capital, Marx identificó claramente la separación de los trabajadores de sus medios de producción, es decir, la expropiación de la tierra de los campesinos, como un momento esencial en la emergencia del capitalismo (Marx, 1990: 873-940). En aquel capítulo, Marx identificó una serie de leyes y medidas políticas que permitieron la mercantilización de la tierra y forzaron la disciplina de mercado, primeros sobre los agricultores capitalistas y más tarde sobre los tra- 
bajadores en Inglaterra. A través de esta larga revisión, Marx quiso subrayar la naturaleza política y coercitiva del capitalismo, que es institucionalizada a través de un régimen peculiar de propiedad privada y formas específicas de intervenciones de clase a través del Estado. Una de las consecuencias del proceso de acumulación primitiva es que, al bloquear y mercantilizar el acceso a la tierra para los campesinos, obliga a estos labradores a reproducirse a través del mercado, vendiendo su fuerza de trabajo a los propietarios de los medios de producción. Inspirándose en la obra de Marx y Karl Polanyi, Ellen Wood nos recuerda que esta expropiación desencadena una de las especificidades fundamentales del capitalismo: la separación formal entre lo económico y lo político (Wood, 1995: 1). Esto distingue a la sociedad capitalista de los anteriores tipos de sociedad en las que el poder económico y el poder político se encontraban fusionados y la posibilidad de apropiarse del excedente y de explotar el trabajo requiere de medios extra-económicos. Wood, refiriéndose a Robert Brenner (1985: 209), caracteriza la forma de relaciones de propiedad que corresponde a las sociedades pre-capitalistas como "propiedad políticamente constituida", porque es el poder político (o el control del Estado) el que da acceso a la propiedad y la apropiación del excedente (Wood, 1999: 49-50). En cambio, una sociedad capitalista, los propietarios de los medios de producción no necesitan detentar el poder político directamente para extraer plusvalía de los trabajadores ya que se basan principalmente en mecanismos económicos para explotar a los trabajadores. Por lo tanto, la posesión de los medios de producción dentro del capitalismo representa una suerte de "propiedad privada absoluta" (Wood, 1999: 29-31, 37-39; Akram, Lodhi y Kay, 2010: 196-198). Sin embargo, esta mercantilización de la tierra, que significa que la forma principal de tener acceso a la tierra es a través de la compra, también tiene consecuencias para los productores capitalistas porque algunos de estos pueden requerir de capital para comprar o alquilar tierra. Este proceso de mercantilización de la tierra somete a los productores capitalistas a la disciplina de la deuda y genera una necesidad de aumentar los ingresos para poder pagar sus préstamos. El poder político del productor capitalista no le servirá de mucho para enfrentar esta necesidad de aumentar sus ingresos y aún menos si alquila su tierra de un terrateniente. Se encuentra obligado de encontrar formas económicas de aumentar su productividad.

Marx pensaba que esta relación entre el capital y propiedad terrateniente era típica de la relación capitalista y desarrolló su teoría de la renta en el volumen 3 de El Capital sobre este modelo. Sin embargo, otros marxistas señalaron muy pronto que esta separación completa de los campesinos de sus medios de producción no siempre fue la for- 
ma principal que tomó el capitalismo en el campo en otras regiones del mundo y que es un proceso mucho más largo de lo que muchos marxistas sugerían. Algunos autores abordaron esta cuestión a través de la idea de distintas vías hacia la agricultura capitalista (Lenin, 1950; Byres, 1996, 2009; Akram-Lodhi y Kay, 2010). En algunas regiones del mundo, como en Prusia, por ejemplo, los terratenientes tradicionales se transformaron en granjeros capitalistas y forzaron a las familias campesinas bajo su subordinación a dejar la producción de subsistencia por trabajo asalariado (Kay, 1974). En otras regiones, como en los Estados Unidos, por ejemplo, los productores familiares siguieron siendo mayoría entre los agricultores durante varias décadas de mediado del siglo XIX hasta el inicio del siglo XX. Combinaban diferentes tipos de relaciones de intercambio con otros actores rurales, como el trabajo asalariado, la aparcería, la producción independiente y la producción mercantil simple, pero todo ellos bajo una lógica capitalista. Byres (1996) se refiere a la primera transición al capitalismo agrario como "capitalismo desde arriba" (o la vía Prusiana) y a la segunda como "capitalismo desde abajo" (o vía Americana).

Lo que sucedió muy a menudo en la mayoría de las regiones del mundo en desarrollo fue que todas estas formas de producción capitalistas coexistieron y se entrelazaron con formas no capitalistas en una sola formación social durante varias décadas. Como muchos estudiosos han destacado, el desarrollo capitalista de los países latinoamericanos se ha caracterizado históricamente por la coexistencia de una gran diversidad de formas de producción, por lo menos desde el siglo XIX hasta bien entrado la primera mitad del siglo XX. Sin embargo, las relaciones sociales capitalistas se generalizaron mucho más rápidamente en países como Argentina, Brasil, Chile y Uruguay, donde la población indígena fue desplazada o aniquilada y la propiedad privada de la tierra impuesta violentamente por las élites gobernantes (Kay, 1980). Pero incluso en estos casos, y a pesar de su subordinación a los terratenientes, los productores campesinos - especialmente cuando los campesinos tienen acceso directo a tierras no mercantilizadasejemplificaban una forma de producción en la que el campesino aún tenía control sobre sus medios de producción y su fuerza de trabajo, así como en cierta medida sobre el grado y la forma de su integración en el mercado (Vergara-Camus, 2016; Boltvinik y Mann, 2016).

Las comunidades campesinas completamente autónomas son ahora la minoría en América Latina. Sin embargo, los productores campesinos de hoy, que dependen del mercado para satisfacer una cantidad sustancial de sus necesidades de subsistencia, así como aquellos que dependen del mercado porque la mayor parte de su producción se vende en el mercado, todavía tienen más margen de ma- 
niobra que productores en condiciones totalmente capitalistas porque pueden ajustar la producción o el consumo de acuerdo con las circunstancias (Bartra, 2006, Vergara-Camus, 2014, Capítulo 4). Sin embargo, para evaluar el grado de autonomía de los diferentes tipos de productores directos, Wood propone una distinción entre "diferentes tipos de dependencia del mercado", asociados a diferentes formas de compulsión del mercado. Algunos productores estarían sujetos al "mercado como una oportunidad" que "se deriva simplemente de la necesidad de obtener bienes de subsistencia mediante el intercambio", mientras que otros se enfrentan al "mercado como un imperativo", lo que significa que están obligados a generar una ganancia para reproducirse (Wood, 2002: 66). La principal distinción es que el primero (típicamente el campesino) se encuentra sometido a la necesidad de vender, mientras que el segundo (típicamente el agricultor capitalista) está obligado a "alcanzar una tasa media de ganancia para sobrevivir, independientemente de sus propias necesidades de consumo (ibídem: 64)". Siguiendo esta distinción, los hogares campesinos con acceso a la tierra tienen por tanto la posibilidad de retirarse del mercado y aprovechar el valor de uso de la tierra y sus productos (Wood, 2009). Dicho esto, cuando la tierra que el campesino controla es insuficiente para satisfacer las necesidades de la unidad familiar y el hogar tiene que recurrir al intercambio mercantil para satisfacer sus necesidades, la monetización puede erosionar las alternativas abiertas a las familias campesinas y conducir a la mercantilización de la agricultura campesina y acelerar los efectos de la dependencia al mercado.

Este proceso también puede conducir a la diferenciación social dentro del campesinado, en la cual un estrato se aprovecha de los miembros de los otros estratos que se encuentran en circunstancias difíciles. Estos "campesinos ricos" pueden acumular tierras de campesinos más pobres y contratarlos como trabajadores asalariados o subordinarlos bajo otras formas. Esto es lo que ha estado ocurriendo en la mayor parte de América Latina a lo largo de las décadas, pero especialmente desde las reformas neoliberales de los años noventa que liberalizaron los mercados de tierras ${ }^{3}$. Sin embargo, la diferenciación campesina por sí sola, entendida como un proceso interno casi natural en cualquier tipo de comunidad campesina, no puede explicar el surgimiento de las relaciones sociales capitalistas. Estas no surgen o

3 Con el giro neoliberal, muchos gobiernos introdujeron programas de titulación de tierra, con el apoyo de Banco Mundial y de otras instituciones internacionales, como parte de una política que buscaba reforzar los derechos de propiedad y favorecer el desarrollo del mercado de la tierra. Para las implicaciones de estas políticas desde una perspectiva de género, véase Deere y León (2001). 
se desarrollan simplemente a partir de la acumulación de riqueza de ciertas familias o grupos dentro de las comunidades campesinas o a una mayor comercialización de la producción. La diferenciación social sustancial dentro del campesinado solo se desarrolla cuando el mercado se convierta en un imperativo y la tierra es mercantilizada e insertada en el circuito del capital. Cuando los campesinos pobres sienten la presión demográfica sobre su tierra y comienzan a experimentar el mercado como un imperativo enajenante, y la diferenciación social se desarrolla en paralelo, los campesinos tratan de abordar esta situación individualmente o a través de su red de parentesco. Sin embargo, a menudo varias fracciones del campesinado buscan una solución política a sus problemas económicos intentando recrear instituciones comunales o crear movimientos sociales (Vergara-Camus, 2009). En otras palabras, en algunos casos algunos de los sectores marginados del campesinado (campesinos pobres, trabajadores rurales sin tierra) buscan recrear políticamente la autonomía campesina desafiando la separación formal de lo económico y lo político. Creemos que a finales de los años noventa e inicio de los dos mil esta primera opción más individualista predominó en Nicaragua, Uruguay y Venezuela, mientras que la segunda opción más colectiva y política se tomó en Brasil, Bolivia, Ecuador y en menor medida en Argentina y Paraguay.

\section{LA SEPARACIÓN DE LO ECONÓMICO Y LO POLÍTICO, LA ACUMULACIÓN POR DESPOSESIÓN Y LA ACUMULACIÓN AMPLIADA DEL CAPITAL}

Puesto que las clases trabajadoras se oponen de diferentes maneras a esta separación formal entre lo económico y lo político, el Estado interviene constantemente para mediar el conflicto entre capitalistas y proletarios, pero siempre sin poner en peligro los derechos de propiedad burguesa (Clarke, 1990: 45). Las clases dominantes tampoco entienden esta separación como algo inmutable. A menudo, pueden utilizar una coyuntura específica que parece a su favor para reorganizar esta separación formal de lo que es del ámbito de lo político (propiedad pública) y lo que es del ámbito de lo económico (la propiedad privada o el mercado). David Harvey (2003), expandiendo el concepto de acumulación primitiva de Marx ha acuñado el término "acumulación por desposesión" para apuntar a este tipo de situaciones. Para él, el neoliberalismo implica mecanismos y procesos muy similares a los que abarca el concepto marxista de la acumulación primitiva. Dentro del neoliberalismo, el problema de la sobreacumulación del capital encuentra su resolución en una toma de posesión por el capital de sectores públicos (salud, educación, pensiones) y de las empresas estatales a través de su privatización por debajo de su valor, así como 
mediante el cercamiento, el acaparamiento y el bio-pirataje de los bienes ambientales como las semillas, los bosques, el agua y otros recursos naturales. Harvey prefiere usar el término "acumulación por desposesión" porque considera que la acumulación primitiva se refiere a la "prehistoria" del capitalismo mientras que estos nuevos procesos de privatización de los comunes están ocurriendo en los países capitalistas avanzados aunque también en los países en desarrollo. Sin embargo, Harvey reconoce que los procesos de acumulación primitiva también están ocurriendo en el Sur, pero argumenta que políticamente es necesario ubicar también estos procesos bajo el paraguas del concepto de acumulación por desposesión (Harvey, 2006: 158).

El análisis de Harvey del neoliberalismo ha sido criticado por varios académicos marxistas (véase el número especial 14(4) de la revista Historical Materialism sobre el nuevo imperialismo de Harvey). Una de las críticas ha sido que el neoliberalismo no consiste simplemente en procesos de acumulación por desposesión. Muchas de las nuevas inversiones y transformaciones generadas por el neoliberalismo son típicas de la reproducción ampliada del capital. Los procesos de "acumulación por desposesión" han estado ocurriendo en América Latina desde por lo menos los últimos dos siglos y, como lo demuestran varios capítulos en este libro, continúan ocurriendo en varias regiones de América Latina (Cáceres, 2015). Sin embargo, las transformaciones recientes en el campo, típicas del desarrollo desigual y combinado del capitalismo, sugieren que en ciertas regiones y sectores - principalmente donde domina el agronegocio, como la soja, el ganado, las frutas y hortalizas, el vino y las bebidas alcohólicas, estamos presenciando estrategias orientadas a la reproducción ampliada del capital (Baraibar, 2014)_. Estos cambios están transformando las formas y relaciones de producción y reproducción de todos los sujetos rurales. La mayoría de los capítulos a este libro sugieren que las estrategias típicas de la acumulación primitiva o la acumulación por desposesión y las estrategias típicas de la reproducción ampliada del capital coexisten y se entrelazan entre sí.

Muchos otros autores aparte de Harvey han señalado que la actual mundialización neoliberal representa otra fase en la expansión de la lógica del capital a todas las esferas de la vida y necesidades humanas que antes no eran mercantilizadas, y que muchas de estas dependen del acceso a la tierra (Smith, 2005; Araghi, 2009). Dentro de este proceso, las relaciones de propiedad juegan un papel crucial. La agenda impulsada por los sectores empresariales y apoyada por los Estados desde principios de los noventa fue pasar de los regímenes nacionales de derechos de propiedad privada limitados por una serie de prerrogativas sociales y políticas a regímenes homogéneos 
de derechos de propiedad con poca o ninguna restricción(o incluso a un régimen global a través de acuerdos comerciales). Obviamente, el derecho de propiedad privada absoluta sobre la tierra representa un elemento crucial en esta expansión de la lógica del capital, ya que la tierra es la base física para cualquier tipo de explotación de los recursos naturales. Por lo tanto, la mundialización neoliberal no solo debe verse como caracterizada por la acumulación por desposesión, sino también como un nuevo intento de reorganizar la separación formal entre lo económico y lo político, desencadenando una variedad de estrategias por parte de diferentes actores que pretenden beneficiarse de esta reestructuración. Sin embargo, desde mediados de los años dos mil la tendencia peculiar, ejemplificada en las estrategias extremadamente diversas de los inversionistas con respecto a la propiedad de la tierra, ha sido que la propiedad privada no es necesariamente la forma preferida de control sobre la tierra por el capital. En muchas circunstancias, los inversionistas capitalistas prefieren alquilar la tierra de propietarios privados o estatales en lugar de comprarla, como se puede observar en particular en las áreas de cultivo de soja de Argentina, Uruguay y Bolivia (ver los diversos capítulos sobre estos países en este libro). Determinar cuáles son las consecuencias de estas estrategias sobre los productores campesinos es de crucial importancia.

\section{LA CATEGORÍA MARXISTA DE RENTA DE LA TIERRA, LA APROPIACIÓN DEL EXCEDENTE Y LA AGRICULTURA CAPITALISTA}

En el capítulo 26 del volumen I de El Capital, Marx (1990) observó que la transformación del campo en Inglaterra había desatado procesos que permitían el desarrollo del capitalismo. En la agricultura, el desarrollo del capitalismo eventualmente subordinaría (o subsumiría) la tierra al capital, o mejor dicho la clase de terratenientes a los granjeros capitalistas (quienes en el caso inglés eran arrendatarios). Sin embargo, este proceso no era automático o lineal, ya que los terratenientes tienen un poder significativo que es además independiente del capital. La dirección que toma este proceso depende del cambio en la correlaciones de fuerzas entre los terratenientes y los capitalistas. En su inacabado volumen 3 de El Capital, Marx (1991) dedicó una cantidad importante de tiempo a reflexionar sobre lo que diferenciaba a la agricultura de los otros sectores productivos. Para él, era el concepto de la renta de la tierra, y no los de ganancia o interés, que permitía llegar a una mejor comprensión de las especificidades de los ingresos generados por la agricultura. Entender los vínculos que existen entre la propiedad de la tierra y las diversas formas de capital era fundamental para Marx. En esta sección, Marx muestra el papel contra-

dictorio de la renta de la tierra y de la propiedad terrateniente dentro 
del modo de producción capitalista y las contradicciones de clase que generan entre capitalistas y terratenientes. Estas contradicciones tienen su origen en el hecho que los terratenientes, por el simple hecho de ser propietarios de tierra, tienen el derecho de cobrar una renta a los agricultores capitalistas.

Marx distinguió tres formas de renta: la renta diferencial I, que se determina sobre la base de la fertilidad natural y la calidad del terreno; la renta diferencial II, que añade a estas cualidades la inversión de capital sobre la terreno; y la renta absoluta de la tierra, que pertenece a los terratenientes simplemente por el hecho de tener un monopolio sobre el acceso a la tierra. Por supuesto, estos tipos de rentas marcan una diferencia en la cantidad de dinero que un propietario puede exigir para el uso de su propiedad. Sin embargo, las dos características comunes y más importantes de todas estas formas de renta de tierra son que representan un costo, o incluso un impedimento, para la acumulación de capital y que en última instancia se basa en un monopolio políticamente otorgado: la propiedad privada de la tierra. Por lo tanto, la renta no debe considerarse como ganancia o interés, como si correspondieran al capital. Son los ingresos de la propiedad terrateniente. Por lo tanto, la propiedad terrateniente no se debe simplemente asociar al capital aunque extrae ingresos, o sea renta, del capital.

Si entendemos el monopolio sobre el acceso que confiere la propiedad como principio fundamental de la renta (lo que la idea de la renta absoluta de Marx subraya), podemos extender el concepto de renta y los dinámicas de extracción de renta a sectores de la economía que se benefician de un monopolio otorgado políticamente. Por ejemplo, los ingresos recibidos por las empresas transnacionales de semillas como Monsanto mediante la aplicación de los derechos de propiedad intelectual reconocidos y recolectados por los Estado nacionales (Filomeno, 2014) deben considerarse como una forma de renta absoluta (véase más adelante). Lo mismo puede aplicarse al sector de los agrocombustibles, ya que el nivel de la mezcla con gasolina y a menudo el precio mismo de los agrocombustibles son establecidos por el Estado. Eso es sin mencionar el hecho que la industria depende en gran medida de los subsidios y créditos estatales (Vergara-Camus, 2015).

Este modelo de la renta de la tierra, en donde el terrateniente tiene la capacidad de extraer renta de los agricultores capitalistas, Marx lo toma nuevamente de la agricultura capitalista en Inglaterra, donde los medianos y grandes agricultores arrendaban tierra de los terratenientes tradicionales (Brenner, 1985). Pero ello no quiere decir que la categoría de la renta nos lleve a pensar la agricultura como si en todas partes siguiera las mismas vías y provoque las mismas dinámicas 
entre las clases como lo hicieron en Inglaterra. En América Latina, por ejemplo, los terratenientes tradicionales solían extraer renta de los campesinos, no en dinero sino en producto o en trabajo o en una combinación de ambos, a través de relaciones sociales pre-capitalistas de subordinación. Durante el último siglo, algunos grandes latifundistas comenzaron a transformarse gradualmente en productores capitalistas, con velocidad, extensión e intensidad variables en los distintos países, en lugar de seguir reproduciéndose como los terratenientes tradicionales extrayendo una variedad de rentas de sus arrendatarios, aparceros y campesinos. Sin embargo, como los capítulos de este libro lo demuestran nuevos tipos de contratos de renta están surgiendo (ver especialmente los capítulos de Lapegna, Piñeiro y Cardeillac, y Marti i Puig y Baumeister en este libro). Las clases rurales adoptan una diversidad de estrategias y ahora algunos terratenientes, medianos, e incluso pequeños productores y comunidades campesinas indígenas, arriendan parte o la totalidad de sus tierras. Se las arriendan al agronegocio, a los agricultores capitalistas o un grupo de inversionistas y administradores agrícolas que tienen el capital, la tecnología y un control parcial sobre la cadena de valor, lográndose así una mayor productividad y rentabilidad comparado con la que el dueño de la tierra podría obtener (Baraibar, 2014). Estos arreglos de arrendamiento tienden a ocurrir en el cultivo de soja y en la explotación de los recursos forestales. Existen aún muy pocos estudios o datos que puedan dar una idea clara de la magnitud de este fenómeno.

Pensamos que existen por lo menos cinco ventajas en utilizar la categoría de renta de tierra de Marx para el análisis de las cuestiones agrarias. En primer lugar, tiene la ventaja de señalar diferentes formas de acumular y controlar la riqueza que, como lo observó Fernando Coronil, abre el análisis a una variedad de actores que la dialéctica capital/trabajo muchas veces subestima. Segundo, subraya la importancia de la tierra para la acumulación de riqueza y poder, así como su papel en la creación de valor en los países subdesarrollados. Para Coronil (1997), agregar la categoría de renta a la clásica dialéctica capital/trabajo, que ve la ganancia e intereses y los salarios como las principales fuentes de ingresos, puede representar una alternativa a la teoría del valor-trabajo. Coronil recupera de Marx las tres fuentes de riqueza (la fórmula de la trinidad) que existen en el modo de producción capitalista y que debería ser la base de una "dialéctica triádica" estructurada en torno al capital, la renta de la tierra y el trabajo. La tercera ventaja de la categoría de la renta de la tierra consiste en que nos permite reunir dinámicas comunes a la agricultura y las industrias extractivas, como la minería, el petróleo y el gas, ya que todas ellas requieren negociar el acceso al recurso natural con los propieta- 
rios de la tierra donde este se encuentre. La cuarta ventaja del uso de la categoría de renta de la tierra es que nos permite examinar el carácter de clase contradictorio del Estado en el proceso de acumulación y apropiación de la plusvalía. Esto es porque el Estado es en última instancia el garante de las relaciones de propiedad, pero también porque muchas veces juega el papel de un terrateniente de los recursos naturales y por lo tanto es capaz de cobrar una renta sobre la tierra a los capitalistas. Finalmente, la quinta ventaja de utilizar la categoría es que resalta la dimensión política del proceso de apropiación y acumulación de riqueza y de capital, que necesariamente debe incluir la forma en que los actores se representan a ellos mismos y al mundo que los rodea, mediante la construcción de discursos y proyectos de clase que justifican sus acciones.

Algunos estudios sobre la economía política de América Latina han utilizado el concepto de renta para explicar el surgimiento y los logros de los gobiernos de izquierda. Weyland (2009), por ejemplo, siguiendo una perspectiva schumpeteriana de la renta, sostiene que el ascenso de la izquierda actual en Bolivia, Ecuador y Venezuela no coincide con el fracaso del neoliberalismo, sino con el descubrimiento o reaparición de grandes rentas de recursos naturales. Weyland argumenta que estos Estados son menos receptivos a las demandas de su ciudadanía, ya que dependen de la renta en lugar de impuestos para sus ingresos. Además esta dependencia en la renta sobre recursos naturales asienta el crecimiento económico de largo plazo sobre bases muy frágiles. Purcell (2013 y en este libro), adoptando en una perspectiva marxista de la renta de la tierra, muestra las contradicciones que atormentaron los intentos de construir una nueva agricultura en una economía capitalista rentista, como la Venezolana, y que fueron frustradas por una crónica sobrevaluación de su moneda. Grinberg (2010), siguiendo también una perspectiva similar, ofrece una clasificación de América Latina en relación al régimen de acumulación que han adoptado los diferentes países. Según él, Sudamérica habría adoptado un régimen de acumulación centrado principalmente en la apropiación de la renta de la tierra, mientras que México, Centroamérica y el Caribe habrían privilegiado la extracción de la plusvalía absoluta, en particular la super-explotación del trabajo. Aunque su clasificación apunta a tendencias importantes de las trayectorias recientes de ciertos países, proponer organizar la inmensa diversidad de formas de acumulación y estrategias de apropiación del excedente bajo una sola lógica nos parece ser demasiado simplista. Para nosotros, Grinberg subestima el dinamismo del sector agropecuario que, como lo demuestran la mayoría de los capítulos de este libro, combinan estrategias muy complejas de "acumulación por 
desposesión" con estrategias típicas de reproducción ampliada del capital, así como con estrategias rentistas.

El punto de partida de la perspectiva teórica sobre el estado que ofrecemos en este capítulo se basa en la separación conflictiva entre lo económico y lo político, que tiende a ser más fluida en sociedades donde las estrategias rentistas juegan un papel importante. Esto es evidente en los casos en que el Estado extrae una renta de la tierra a cambio de derechos de explotación de los recursos naturales. Esto es así porque la centralidad de la renta sitúa al Estado en el centro del proceso de acumulación y configura las estrategias de apropiación y acumulación de riqueza de los diferentes actores dentro de la sociedad. Pero aun en los casos donde el Estado no es el propietario de los recursos naturales, la propiedad políticamente constituida o el acceso a cargos o funcionarios estatales siguen siendo formas importantes de apropiación de la plusvalía en América Latina. Por lo tanto, el Estado debe ser visto también como un espacio de acumulación de riqueza, ya que los actores privados intentan acceder a la renta de la tierra que le corresponde al Estado o acceder a los funcionarios estatales que toman decisiones políticas con consecuencias económicas, porque ello le permitirá a un empresario privado cobrar una renta absoluta.

Esta perspectiva propone una conceptualización diferente del Estado que va más allá, en primer lugar, del supuesto generalizado de que el Estado en los países periféricos es una versión incompleta o truncada del Estado capitalista avanzado; en segundo lugar, del debate marxista en torno a la autonomía relativa del Estado, donde el Estado desempeña el papel del capitalista general; y en un tercer lugar, de la perspectiva neo-weberiana que le reconoce una racionalidad por encima de la sociedad y asienta esa racionalidad en el carácter de su burocracia. Desde nuestra perspectiva, el Estado a veces puede actuar de manera autónoma a través de sus políticas concretas, porque controla ciertos sectores del circuito de producción de valor, es decir, diferentes tipos de renta o actividades productivas, y en otras ocasiones actúa como una institución con poca autonomía, subordinada a actores nacionales e internacionales. Esto no se debe al carácter del Estado en sí, sino al hecho que el Estado es un espacio de lucha de clase. De esta manera, al igual que Wolford et al (2016), entendemos el Estado como un espacio contradictorio alrededor del cual las diferentes clases y fracciones de clase se enfrentan y despliegan sus estrategias. En cualquiera de estas circunstancias, el discurso de Estado adquiere una importancia peculiar porque revela cómo los funcionarios estatales intentan moldear la realidad. El discurso del Estado no es simplemente una reflexión super-estructural del desarrollo estructural del modo de producción sino que debe ser entendido como un dispositivo 
fundamental para que el Estado ejerza su poder a través de políticas y programas, lo que a su vez permite la construcción de este discurso.

Para el análisis de los gobiernos de izquierda, pensamos que conceptualizar al Estado latinoamericano como un Estado que tiene características rentistas nos permite entender las políticas estatales como el resultado de las luchas de clase frente al (y a través del) Estado, observando cómo los funcionarios estatales asignan recursos y cómo las diferentes clases intentan ocupar las instituciones del Estado y buscar concesiones de él.

\section{PANORAMA DE LAS PRINCIPALES TENDENCIAS EN EL CAMPO LATINOAMERICANO}

Antes del giro neoliberal, la estructura agraria de América Latina estaba dominada por una poderosa clase terrateniente, cuyo poder tenía su origen en el período colonial, el cual se consolidó mediantes las reformas liberales de fines del siglo XIX, reforzando la estructura agraria latifundio-minifundio. Dependiendo del país, esta clase participaba de diferentes maneras en el sector exportador y mantenía diferentes niveles de influencia y poder sobre otras clases rurales (agricultores capitalistas, arrendatarios, campesinos, proletarios rurales y comunidades indígenas), así como sobre la política nacional. En muchos países, de los años sesenta hasta los años ochenta del pasado siglo, las clases terratenientes fueron uno de los principales blancos de los movimientos revolucionarios y reformistas, lo que llevó a que varios gobiernos modificaran los sistemas de tenencia de la tierra y limitaran la extensión de la propiedad privada de la tierra (Kay, 1998). En la década del cincuenta, Bolivia implementó una de las más importantes reformas agrarias de la región en el altiplano, pero permitió la aparición de grandes propiedades en las tierras bajas del Oriente (Bottazzi y Rist, 2012; Urioste y Kay, 2008). Ecuador llevó a cabo una reforma agraria moderada en los años sesenta y setenta (Bretón Solo De Zaldívar, 2008). En Nicaragua, tras la revolución de 1979, el gobierno sandinista produjo la reforma agraria más radical de los años ochenta que, aunque se ha visto una cierta reversión en los años noventa, aún le permite a los campesinos de controlar una proporción importante de la tierra agrícola (véase Martí i Puig y Baumeister en el capítulo de este libro). En Brasil, mediante lo que los estudiosos llaman la "modernización conservadora de la agricultura", el gobierno reestructuró el campo hacia une vía claramente capitalistas y expulsó a millones de familias campesinas. Pero en las últimas dos décadas, en respuesta a la presión social de los movimientos desde abajo, el Estado brasileño se ha visto forzado a distribuir una cantidad substancial de tierra (1,3 millones de hectáreas según las fuentes oficiales), que no tienen 
ningún precedente histórico. Sin embargo, considerando el tamaño del país y una nueva ronda de expansión de grandes propiedades en la última década y media, esta distribución sigue siendo insuficiente como para incidir sobre la distribución tierra altamente desigual que ha siempre caracterizado a Brasil. De hecho, desde que Dilma Rousseff se convirtió en Presidenta en 2010, la reforma agraria en gran medida se ha estancado (Sauer y Mészáros, en este libro).

Con el giro neoliberal en los años ochenta y noventa en América Latina, el sector exportador ha adquirido una importancia aún mayor que durante el período de industrialización por sustitución de importaciones, que se centró principalmente en el mercado interno. Después de una década y media de difícil reestructuración, que incluye reformas a los derechos de propiedad sobre la tierra, la liberalización de la economía y la apertura hacia el mercado mundial, los años dos mil fueron marcados por un nuevo dinamismo en el sector exportador basado en la explotación de los recursos naturales. Este auge en las exportaciones de productos primarios (agricultura, silvicultura, pesca, minería, gas y petróleo) se debe en gran medida a la creciente demanda de materias primas por China, quien se convirtió en un actor central en el mercado mundial. Esta nueva ola de desarrollo capitalista, impulsado por las exportaciones, ha sido caracterizada como "neoextractivista" (Gudynas, 2009; Burchhardt y Dietz, 2014) y señala una re-primarización de las economías de la región (Cypher, 2010; Acosta, 2013b). La demanda mundial creciente por productos primarios ha aumentado su rentabilidad y atraído más inversiones de capital, tanto nacionales como extranjeras, en el sector agropecuario. Por otra parte, el capital de otros sectores económicos como la minería, la industria, el comercio y las finanzas han invertido en actividades agrícolas mucho más que en el pasado y han fomentado el agroextractivismo (Petras y Veltmeyer, 2014).

Aunque algunos estudiosos sostienen que los países latinoamericanos han estado reembarcándose en la trayectoria de desarrollo orientado a la exportación de productos primarios establecida a finales del siglo XIX (Cypher, 2010), esta nueva fase, sin embargo, difiere de fases anteriores de muchas maneras. Uno de los nuevos fenómenos ha sido la importante reestructuración de la producción agrícola hacia las exportaciones agrícolas no tradicionales (soja, flores cortadas, frutas, productos hortícolas), que está poniendo en riesgo la seguridad alimentaria y generalizando las condiciones laborales más precarias como el trabajo temporal (Kay, 2015). Otra diferencia importante con las fases anteriores de desarrollo es que este proceso de reestructuración involucra una variedad de actores y complejas alianzas y configuraciones de clase que varían mucho en cada país, pero 
en las que los grandes agricultores capitalistas nacionales y el agronegocio nacional y transnacional desempeñan un papel fundamental. Además del papel de los inversionistas extranjeros tradicionales, estadounidense y europeos, los estudios recientes sobre el acaparamiento de tierras en América Latina han destacado la "latinización" de la inversión de capital (Borras et al., 2012) para señalar la creciente incursión del capital agrario brasileño y argentino en los otros países latinoamericanos. Este capital "translatino" es particularmente importante en los países vecinos de Argentina y Brasil, como Bolivia, Paraguay y Uruguay, donde han establecido una posición dominante en el cultivo de soja (véase los capítulos de Piñeiro y Cardeillac, Webber, Ezquerro Cañete y Fogel en este libro).

Aunque los productores campesinos sigan desempeñando un papel importante en la producción alimentaria a nivel nacional, la agricultura se ha vuelto cada vez más dominada por el agronegocio y el gran capital. La antigua clase terrateniente latifundista ha sido barrida o se ha transformado en una clase de productores capitalistas. Los campesinos que residían dentro del latifundio y que tenían acceso a una pequeña parcela para su subsistencia a cambio de trabajar para el terrateniente sin pago o por un salario reducido constituían la principal fuente de mano de obra para los latifundistas. Estos campesinos que pagaban una renta en trabajo por el usufructo de la parcela han sido gradualmente eliminados por la mecanización del latifundio y en algunos casos por la introducción de leyes laborales que prohibían el pago de renta en trabajo ya que era considerado un remanente feudal y opresivo que impedía el desarrollo del capitalismo en el campo. Por lo tanto, se han intensificado los procesos de proletarización campesina y se ha generalizado el trabajo asalariado predominantemente de tipo temporal y que ya no reside en la finca - la cual ahora funciona estrictamente como una empresa agrícola capitalista- Las tecnologías tradicionales de uso intensivo de mano de obra del pasado también han sido reemplazadas por las tecnologías agroindustriales intensivas en capital que ahorran mano de obra. El uso de tecnología dependiente de combustibles fósiles e insumos químicos también ha tenido importantes impactos ambientales negativos, como la contaminación de las aguas de los sistemas fluviales y las fuentes acuíferas, los problemas de salud de los trabajadores debido a la intensificación del proceso laboral y los problemas de salud de las poblaciones locales debido a la fumigación aérea (Otero y Lapegna, 2016).

Estos nuevos procesos de acumulación de capital aumentaron la concentración de la tierra, pero sobre todo la concentración del mercado y del capital. En la mayoría de los países de la región, con el giro neoliberal en los años ochenta y noventa del siglo pasado, el trabajo 
rural se debilitó con la desarticulación de los sindicatos mediante de nuevas legislaciones laborales favorables a las empresas, la reestructuración de las relaciones laborales, la subcontratación (o tercerización) y la emigración rural de trabajadores a los centros urbanos de los países más ricos (Ortiz et al., 2013). Solo en Brasil algunos sindicatos rurales pudieron alcanzar algunos logros a través de la negociación colectiva (Selwyn, 2012). Los pequeños productores campesinos y familiares son ahora mucho más dependientes del mercado, las relaciones salariales se han vuelto mucho más importantes para la reproducción social de la población rural y la semi-proletarización de la fuerza laboral rural es casi universal. A pesar de que las familias campesinas con acceso a la tierra puedan en teoría refugiarse en la producción de subsistencia, el mercado se está convirtiendo cada vez más en un imperativo para su supervivencia. Pero todavía hoy en día, los estratos más pobres del campesinado (particularmente, pero no exclusivamente, en las regiones indígenas) continúan reproduciéndose a través de relaciones sociales que no son del todo capitalistas, como el control de tierras bajo tenencia colectiva, el uso extensivo de la mano de obra familiar no remunerada y el intercambio no monetarizado, aunque estén insertos en el circuito nacional o global del capital mediante la comercialización de sus productos. Sin embargo, por lo general, estas prácticas parecen ser en la gran mayoría de los casos mecanismos de defensa frente a la marginación social y solamente en algunos casos peculiares forman parte de una estrategia consciente de construcción de autonomía frente al mercado (Vergara-Camus, 2016; 2014) o de lo que Van der Ploeg (2010) llama el "distanciamiento activo del mercado". La ausencia de una verdadera reforma agraria a favor de los campesinos pobres y campesinos sin tierra en América Latina después de los años setenta (excepto en Nicaragua), la desaparición del apoyo estatal a los campesinos y pequeños productores familiares y la creciente presión demográfica dentro de las comunidades campesinas e indígenas erosionaron la autonomía campesina y aumentaron la diferenciación social dentro del campesinado. En ese contexto, la resistencia campesina e indígena al neoliberalismo de los años noventa fue de hecho una reacción a estos cambios y generó la unidad de los diferentes estratos de campesinado (campesinos pobres con tierra, campesinos sin tierra, trabajadores rurales semi-proletarizados) en torno a unas demandas por una nueva reforma agraria, el apoyo renovado a la agricultura campesina y familiar y el ataque ideológico al agronegocio.

Esta nueva configuración de clase que apoya el neo-extractivismo ha dado lugar a la creciente mercantilización de la naturaleza, a un nuevo proceso de cercamiento y acaparamiento de la tierra, que algunos autores han caracterizado como afín a la llamada acumulación 
primitiva de Marx (Akram-Lodhi, 2007), otros como casos de la acumulación por desposesión (Harvey, 2003; Araghi, 2009) y otros como señalando el paso de la subsunción formal a la subsunción real del trabajo/ tierra /naturaleza al capital (Smith, 2006; Moore, 2010). Si bien los sectores extractivos despliegan una gran variedad de estrategias de acumulación de riqueza, si nos detenemos en la concesión de los derechos de propiedad privada sobre los recursos naturales y los territorios, parece que estamos asistiendo al surgimiento de una nueva forma capitalista de propiedad privada políticamente constituida, que a veces otorga la capacidad de extraer una renta absoluta. Por ejemplo en Brasil, desde 2005, el derecho de propiedad intelectual (PI) de Monsanto sobre las semillas de soja Roundup Ready le permite a la empresa transnacional cobrar el uno por ciento en regalías sobre el valor de la soja vendida a empresas procesadoras y comercializadoras, mientras que en Paraguay el mismo mecanismo se aplica pero el monto es sujeto a negociaciones anuales (Filomeno, 2014: 449, 453; Ezquerro-Cañete, 2016). Puesto que la concesión de los derechos de explotación de los recursos naturales como el marco legal para la protección y aplicación de los derechos de PI dependen en gran medida del Estado, la forma de acceder a los funcionarios estatales o la forma de influir en el proceso de formulación de políticas se han convertido en cuestiones cruciales para el capital.

De la misma manera, el proceso de subsunción real del trabajo y de la tierra al capital en América Latina toma diferentes formas en distintos lugares, en parte debido al régimen de propiedad, y conduce a estrategias muy variadas de control de la producción. Entre los grandes productores agrícolas más dependientes del mercado (Argentina, Brasil y Uruguay), esto está llevando a aquellos que tienen suficientes recursos o acceso al crédito a adoptar tecnologías intensivas en capital y formas de producción que aumenten la productividad de la tierra y el trabajo, o a invertir en infraestructuras para acortar el tiempo para engordar el ganado (Lepegna, en este libro; Piñeiro y Cardeillac, en este libro). Entre los productores campesinos con suficiente tierra, esto ha provocado un movimiento hacia las actividades comerciales, como la soja en América del Sur o la ganadería en Nicaragua (pero aún bajo modelos extensivos de baja productividad). Sin embargo, es difícil decir si este reciente movimiento hacia los cultivos comerciales ha sido sentido como un "imperativo" o una "oportunidad" por parte de los productores campesinos, ya que esto puede depender en parte de su nivel de endeudamiento y de la cantidad de tierra que controlan. Dentro del agronegocio, las estrategias en cuanto a la producción agrícola en sí han variado mucho. Estas van desde la compra de tierras y la participación directa en la producción hasta el arrendamiento de 
tierras de los terratenientes. En Argentina, Brasil y Uruguay, todos los países en los que el campo ha sido capitalista desde hace varias décadas ya, el precio de la tierra se ha convertido en un factor importante en la decisión de comprar o arrendar. Sin embargo, la tendencia general inconfundible es la creciente concentración de la cadena global de valor, tanto en las actividades anteriores a la agropecuaria (upstream), como las semillas y los insumos, como en las actividades posteriores (downstream), como la transformación, la comercialización y la exportación. En ambos extremos de las cadenas de valor, empresas transnacionales como Archer Daniels Midland (ADM), Bunge, Cargill, Louis Dreyfus y Monsanto acaparan la mayor parte del mercado (ver el capítulo de conclusión de este libro).

Algunas de las estrategias de acumulación de riqueza en la agricultura han implicado la desposesión mediante la toma de control de recursos naturales públicos o comunales como la tierra y los bosques. Pero muchos otros casos las estrategias de acumulación de riqueza combinan fluidamente diversos mecanismos como la apropiación de la renta absoluta (como las regalías de las semillas), la renta diferencial I o II (como la compra o la renta de tierras altamente fértiles), la extracción de plusvalía absoluta (intensificando o reorganizando el proceso de trabajo, extendiendo las horas de trabajo y evitando aumentos salariales), la extracción de la plusvalía relativa (aumentando la productividad a través de la mecanización e insumos químicos), todos ellos fuertemente apoyado o con la participación directa del Estado nacional y el capital transnacional (Burbach y Flynn, 1980).

De hecho, el Estado jugó un papel central en este movimiento que llevó a la dependencia de los productores del mercado y a la subsunción real del trabajo y la tierra al capital porque las políticas estatales fueron las que impulsaron el auge del agronegocio (White et al., 2013). En Brasil, durante la dictadura militar, por ejemplo, fue un generoso plan de crédito a finales de los años sesenta el que aumentó la producción de cereales y granos y convirtió al país en una nueva y poderosa potencia agrícola (véase Sauer y Mészáros en este libro). En Bolivia, durante la dictadura de Hugo Banzer (1971-1978), el Estado distribuyó tierra a los grandes terratenientes de la Media Luna y convirtió a la región en el sector agrícola capitalista más dinámico del país (véase Webber en este libro). En la mayoría de los países latinoamericanos, los ministerios de agricultura a menudo eran dirigidos por representantes de grandes terratenientes o del agronegocio o por personas cercanas a ellos. De esta forma, pudieron influir directamente en las políticas y extraer concesiones como reformas institucionales que promueven la propiedad privada, subsidios y créditos, incentivos fiscales y normas ambientales favorables. 
La embestida del capital y la creciente mercantilización de la naturaleza desencadenaron una serie de contra-movimientos. En las dos últimas décadas hemos estado presenciando el surgimiento de movimientos campesinos e indígenas, movimientos ecológicos, movimientos contra la minería, etc., que se resisten al avance del capital y a la firma e implementación de acuerdos de libre comercio. En las últimas décadas también hemos presenciado la creciente disputa entre capital y trabajo por territorio o lucha por la autonomía de los pueblos indígenas. Algunos de estos movimientos, como los Zapatistas y el MST, han sido capaces de proteger o lograr el acceso a la tierra y han reinventado las comunidades campesinas (Vergara-Camus, 2014). Muchos otros movimientos en toda la región, especialmente en Bolivia y Ecuador, también fueron capaces de movilizar a sus miembros contra los gobiernos neoliberales y proponer patrones de desarrollo alternativo orientados hacia una mayor autosuficiencia y autonomía campesina, la agricultura orgánica, la agroecología, los mercados locales y la soberanía alimentaria, todo ellos sostenido por una nueva reforma agraria (Brabazon y Webber, 2014). En Bolivia y Ecuador, los movimientos rurales también formaron parte de una amplia coalición de movimientos contra el neoliberalismo que derribó a varios gobiernos a finales de los años noventa y principios de los dos mil. La Confederación Latinoamericana de Organizaciones del Campo (CLOC) y La Vía Campesina se beneficiaron enormemente de la vitalidad de estos movimientos rurales.

Todas estas tendencias, procesos y desarrollos son el resultado de importantes reconfiguraciones de clase y el surgimiento de nuevas relaciones de clase, más allá de que sean o no interpretados en términos de clase por los diferentes sujetos rurales. Si tomamos una perspectiva histórica para entender estas transformaciones, emergen algunas preguntas sobre las relaciones de clase: ¿Quiénes son los actores dominantes y qué tipo de configuraciones de clase estructuran hoy el campo en los diferentes países latinoamericanos? ¿Qué tipo de alianzas de clases existían en la cima de la pirámide social nacional entre las clases terratenientes, las burguesías agrarias y el capital extranjero hasta los años dos mil y cómo han venido cambiando hasta hoy? De la misma manera, ¿qué tipo de alianzas de clase entre las clases subalternas permitieron la movilización de los campesinos e indígenas hasta los años dos mil y cómo la llegada de la izquierda al poder transformó estas alianzas?

\section{LAS CUATRO PROBLEMÁTICAS DEL LIBRO}

Para llevar a cabo la evaluación de las políticas agrarias de los gobiernos de izquierda, los capítulos de este libro abordan cuatro problemáticas interrelacionadas. 
La primera gira en torno a la relación entre los movimientos campesinos, los partidos políticos y el Estado. Este es probablemente el tema sobre el cual se ha escrito más pero el cual menos ha sido teorizado o seriamente analizado de todos. Los análisis generalmente explican lo acontecido a este nivel recurriendo a conceptos como la cooptación, la traición de clase, la revolución pasiva o la gubernamentalidad. Pensamos que un análisis serio requiere de una evaluación detallada del nivel de autonomía política que los movimientos tenían respecto a partidos políticos y los líderes políticos, así como el poder y las estrategias que las diferentes clases rurales movilizaron en su lucha por influir u ocupar el Estado, y las consecuencias que estas decisiones tuvieron sobre su capacidad de representar un contrapeso a los actuales gobiernos de izquierda.

La segunda problemática se refiere al grado de autonomía indígena y campesina que se puede adquirir y mantener en medio de la globalización de la agricultura y la expansión del agronegocio. Durante las luchas de los años noventa, las demandas y el discurso de los campesinos consistían en demandas para aumentar su control sobre los recursos naturales, sobre todo sobre la tierra, y el territorio en el caso de los movimientos indígenas, acceder a financiamiento y formas distintas y más justas de integración al mercado.

El análisis del grado de autonomía campesina e indígena se vincula con una tercera problemática que tiene que ver con el legado de los patrones históricos de distribución de la tierra, la base institucional de control de la tierra y los sistemas de tenencia de la tierra de los campesinos sobre las políticas de la izquierda. En términos generales, estos diferentes legados influyen enormemente en la capacidad del sector campesino de resurgir y seguir siendo un importante actor político, pero también ha determinado el tipo de control que el capital y el agronegocio pudo tener sobre la agricultura y la mano de obra rural (Vergara-Camus, 2014; Puig y Baumeister, en este libro). Por ejemplo, las reformas agrarias que modificaron los regímenes de propiedad en lugares como Bolivia (1954), Ecuador (1964, 1973) y Nicaragua (1979) inicialmente fortalecieron a los productores campesinos y en cierto grado limitaron la diferenciación de clases, mientras que la ausencia de reformas agrarias y el predominio de la propiedad privada de la tierra en lugares como Argentina, Brasil, Paraguay, Uruguay y Venezuela facilitaron la expansión de la agricultura capitalista de mediana y gran escala. La forma en que cada uno de estos gobiernos de izquierda ha abordado este legado explica en gran medida el grado de continuidad y ruptura con los gobiernos anteriores.

Por último, estas diferentes problemáticas desembocan en una cuarta que consiste en la cuestión más amplia acerca del posible sur- 
gimiento de un modelo alternativo de desarrollo agrícola, mediante la adopción de la soberanía alimentaria y del Buen Vivir como política de Estado. En el caso de Bolivia y Ecuador en particular, la incorporación el Buen Vivir y la soberanía alimentaria en sus respectivas Constituciones se han presentado como una contribución crucial de los movimientos campesinos e indígenas a la transformación del modelo de desarrollo. Algunos estudios críticos están surgiendo sobre el tema, como los de Gudynas (2009) y Acosta (2013a), pero muchos autores prefirieron hacer intervenciones generales, éticas y normativas. Sin embargo, la cuestión de si los conceptos de soberanía alimentaria y Buen Vivir han constituido la base de un modelo agrícola alternativo - o por lo menos de los programas estatales orientados a los pequeños productores- aún necesita ser evaluada críticamente. Del mismo modo, la evaluación de si estos conceptos mismos pueden ser la base de un modelo alternativo de agricultura o de futura movilización campesina e indígena contra estos y otros gobiernos también requiere una evaluación crítica.

El examen de estas cuatro problemáticas comienza con un capítulo de Carmen Diana Deere que evalúa como los gobiernos de izquierda de Brasil, Bolivia, Ecuador y Venezuela tradujeron las presiones de los movimientos de mujeres rurales en políticas de titulación de tierras para mujeres. Si bien se han logrado algunos avances hacia la obtención de derechos a la tierra para las mujeres, aunque esto en algunos países más que en otros, la meta de una tenencia de la tierra igualitaria entre genero está lejos de haberse alcanzado. Continúa con un capítulo de Arturo Ezquerro-Cañete y Ramón Fogel que analiza el golpe constitucional instigado por la clase terrateniente contra el presidente Fernando Lugo en 2012 en Paraguay. Este golpe de Estado, aunque el resultado de un proceso histórico específico de formación de clases y del Estado en Paraguay, podría ser visto como el preludio del golpe civil que la presidenta Dilma Rousseff sufriría en Brasil en 2016. El siguiente capítulo sobre Venezuela, escrito por Tom Purcell muestra cómo el Estado Venezolano, a pesar de derramar enormes recursos financieros, redistribuir grandes cantidades de tierras, crear nuevas instituciones estatales y movilizar a los funcionarios estatales para construir una agricultura basada en la agricultura campesina, fracasó rotundamente en su intento de superar el legado histórico del capitalismo rentista. Además, algunas políticas económicas del gobierno desencadenaron la práctica de bachaqueo, lo que socavó los valiosos esfuerzos de crear un modelo agrícola alternativo. El capítulo de Pablo Lapegna sobre los gobiernos de los Kirchner en Argentina nos traslada de un proceso contradictorio a otro en el cual el peso de la historia nacional de formación de clases y del Estado es también 
palpable. Adoptando una perspectiva gramsciana, Lapegna muestra cómo los movimientos campesinos argentinos decidieron una vez más confiar en los políticos peronistas (Néstor Kirchner y más tarde su esposa Cristina Fernández de Kirchner), quienes construyeron un discurso hegemónico que incorporaba a las clases populares y que atacaba retóricamente a la "oligarquía terrateniente". Todo ello al mismo tiempo en que subvencionaban a la agricultura capitalista de grande escala y el agronegocio y mantenían una alianza política en diferentes provincias rurales con gobernadores conservadores cercanos a los intereses de los grandes terratenientes.

Si bien Paraguay, Venezuela y Argentina son casos donde los movimientos campesinos no eran los más activos de la región, los casos de Bolivia y Ecuador parecían ser lo contrario. El capítulo sobre Bolivia, escrito por Jeffery Webber, demuestra que los movimientos campesinos e indígenas eran importantes en la primera fase de los gobiernos de Morales cuando tuvo que enfrentarse a un movimiento secesionista de las provincias de la Media Luna dirigido por grandes agricultores capitalistas. Pero siguiendo una vía típica de lo que Gramsci llamó revolución pasiva, el gobierno de Morales en su segunda fase estableció una alianza con los capitalistas agrarios de la Media Luna, lo que se tradujo en una reforma agraria bastante ambigua y contradictoria. El capítulo de $\mathrm{Pa}$ trick Clark sobre Ecuador cuestiona también la fuerza política real que tenían los movimientos campesinos e indígenas y su capacidad en influir en las políticas del gobierno de Rafael Correa. A través de una descripción de varias de sus principales políticas agrícolas, Clark demuestra que no fueron la soberanía alimentaria o el buen vivir que orientaron sus políticas, sino que fue el neodesarrollismo extractivista y que los movimientos sociales no pudieron influir en ellos de ninguna manera.

El capítulo de Diego Piñeiro y Joaquín Cardeillac sobre Uruguay nos remite a un caso en que los movimientos rurales de las clases subalternas son sumamente débiles y donde la historia parece repetirse, ya que muestra cómo la distribución desigual de la tierra a principios del siglo XXI se asemeja a la de principios del siglo XX. El gobierno de izquierda del Frente Amplio siguió promoviendo los intereses del agronegocio, aunque mejoró las condiciones de vida y de trabajo de los asalariados rurales debido a su compromiso ideológico. El capítulo de Salvador Martí i Puig y Eduardo Baumeister sobre Nicaragua es también un caso de movimientos campesinos debilitados y con poca influencia en las políticas. También es un caso en el que el legado histórico de la reforma agraria del régimen sandinista (1979-1998) pesa más en la capacidad actual de los campesinos pobres de sobrevivir, y de los campesinos medios de integrarse en el mercado que las políticas actuales del presidente Daniel Ortega. 
Este libro concluye con dos capítulos que cierran el círculo. El capítulo de Sérgio Sauer y George Mészáros sobre Brasil es un caso en el que los movimientos rurales eran fuertes al inicio del gobierno del Partido de los Trabajadores, pero en el cual el agronegocio supera en gran medida la capacidad de los movimientos rurales para impulsar sus intereses en todas las diferentes instituciones del Estado. Como se mencionó anteriormente, también es el último caso de un golpe constitucional contra un gobierno de izquierda electo democráticamente. Finalmente, nuestro capítulo de conclusión reúne todos los casos para identificar las tendencias generales y las divergencias en las transformaciones agrarias, así como en las políticas públicas de los gobiernos de izquierda, principalmente las que están orientada hacia al agronegocio, los campesinos y los trabajadores rurales. La conclusión trata también de explicar el carácter limitado de las políticas de los gobiernos de izquierda y entender sus posibles consecuencias sobre los movimientos campesinos e indígenas. En gran medida, nuestro análisis de ello apunta al peso importante que juega el legado histórico del siglo XX en la economía política de los gobiernos de izquierda en América Latina.

\section{BIBLIOGRAFÍA}

Acosta, A. 2013a El Buen Vivir. Sumak Kawsay, una oportunidad para Imaginar otros mundos (Barcelona: Icaria).

Acosta, A. 2013b "Extractivism and neoextractism: two sides of the same curse" en Lang, M. y Mokrani, D. (eds.) Beyond Development: Alternative Visions from Latin America (Ámsterdam: TNI).

Akram-Lodhi, A. H. 2007 "Land, markets and neoliberal enclosure: An agrarian political economy perspective" en Third World Quarterly, 28 (8).

Akram-Lodhi, A. H. y Kay, C. (eds.) 2009 Peasants and Globalization: Political Economy, Rural Transformation and the Agrarian Question (Londres: Routledge).

Akram-Lodhi, A. H. y Kay, C. 2009 "The agrarian question: peasants and rural change" en Akram-Lodhi, A. H. y Kay, C. (eds.) Peasants and Globalization. Political Economy, Rural Transformation, and the Agrarian Question (Londres: Routledge).

Akram-Lodhi, A. H. y Kay, C. 2010 "Surveying the agrarian question (part 1): unearthing foundations, exploring diversity" en Journal of Peasant Studies, 37 (1).

Araghi, F. 2009 "The invisible hand and the visible foot: peasants, dispossession and globalization" en Akram-Lodhi A. H. y Kay 
(eds.) Peasants and Globalization. Political Economy, Rural Transformation, and the Agrarian Question (Londres: Routledge).

Baraibar, M. 2014 Green Deserts or New Opportunities?: Competing and Complementary View son the Soybean Expansion in Uruguay 2002-2013 (Estocolmo: Department of Economic History, Stockholm University). Disponible en <www.sub.su.se>.

Barrett, P., Chávez, D. y Rodríguez-Garavito, C. (eds.) 2008 The New Latin American Left: Utopia Reborn (Londres: Pluto Press).

Bartra, A. 2006 El capital en su Laberinto. De la renta de la tierra a la renta de la vida (México DF: Editorial Ítaca).

Bernstein, H. 2014 "Food sovereignty via the "peasant way": a sceptical view" en Journal of Peasant Studies, 41 (6).

Boltvinik, J. y Mann, S. A. 2016 Peasant Poverty and Persistence in the Twenty-First Century: Theories, Debates, Realities and Policies (Londres: Zed Books).

Borras Jr., S. M. 2008 "La Vía Campesina and its global campaign for agrarian reform" en Journal of Agrarian Change, 8 (2-3).

Borras Jr., S. M.; Kay, C.; Gómez S. y Wilkinson, J. 2012 “Land grabbing and global capitalist accumulation: key features in Latin America" en Canadian Journal of Development Studies, 33 (4).

Bottazzi, P. y Rist, S. 2012 "Changing land rights means changing society: The sociopolitical effects of agrarian reforms under the government of Evo Morales" en Journal of Agrarian Change, 12 (4).

Brabazon, H. y Webber, J. R. 2014 "Evo Morales and the MST in Bolivia: continuities and discontinuities in agrarian reform" en Journal of Agrarian Change, 14 (3).

Brand, U. y Görg, C. 2008 "Post-Fordist Governance of Nature: The Internationalization of the State and the case of Genetic Resources. A Neo-Poulantzian Perspective" en Review of International Political Economy, 15 (4).

Brenner, R. 1985 “The Agrarian Roots of European Capitalism” en Aston, T. H. y Philpin, C. H. E. (eds.) The Brenner Debate. Agrarian Class Structure and Economic Development in Preindustrial Europe (Cambridge: Cambridge University Press).

Bretón Solo De Zaldívar, V. 2008 "From agrarian reform to ethnodevelopment in the highlands of Ecuador" en Journal of Agrarian Change, 8 (4).

Burbach, R. y P. Flynn 1980 Agribusiness in the Americas: The Political Economy of Corporate Agriculture (Nueva York: Monthly Review Press). 
Burchardt, H.-J. y Dietz, K. 2014 “(Neo-)estractivism - A new challenge for development theory from Latin America" en Third World Quarterly, 35 (3).

Byres, T. J. 1996 Capitalism from Above and Capitalism from Below: An Essay in Comparative Political Economy (Londres: Macmillan Press).

Byres, T. J. 2009 "The landlord class, peasant differentiation, class struggle and the transition to capitalism" en The Journal of Peasant Studies, 36 (1).

Cáceres, D. M. 2015 “Accumulation by dispossession and socioenvironmental conflicts caused by the expansion of agribusiness in Argentina" en Journal of Agrarian Change, 15 (1).

Cameron, M. A. y Hershberg, E. (eds.) 2010 Latin America's Left Turns: Politics, Policies, and Trajectories of Change (Boulder: Lynne Rienner).

Castañeda, J. G. y Morales, M. A. (eds.) 2008 Leftovers: Tales of the Latin American Left (Londres: Routledge).

Clark, P. 2016 "Can the state foster food sovereignty? Insights from the case of Ecuador" en Journal of Agrarian Change, 16 (2).

Clarke, S. 1990 "The state debate" en Clarke, S. (ed.) The State Debate (Londres: Macmillan).

Córdoba, D. y Jansen, K. 2014 “The Return of the state: neocollectivism, agrarian politics and images of technological progress in the MAS era in Bolivia" en Journal of Agrarian Change, 14 (4).

Coronil, F. 1997 The Magical State. Nature, Money and Modernity in Venezuela (Chicago: University of Chicago Press).

Cypher, J. M. 2010 “South America's Commodities Boom:

Developmental Opportunity or Path Dependent Reversion?" en Canadian Journal of Development Studies, 30 (3-4).

Deere, C. D. y León, M. 2001 "Who Owns the Land? Gender and Land-Titling Programmes in Latin America" en Journal of Agrarian Change, 1 (3).

Deere, C. D. y Royce, F. S. (eds.) 2009 Rural Social Movements in Latin America (Gainesville, FL: University Press of Florida).

Desmarais, A. 2007 La Via Campesina: Globalization and the Power of Peasants (Londres: Pluto Press).

Ellner, S. 2014 Latin America's Radical Left (Lanham, MA: Rowman \& Littlefield). 
Enríquez, L. J. y Newman, S. J. 2016 "The conflicted state and agrarian transformation in pink tide Venezuela" en Journal of Agrarian Change, 16 (4).

Escobar, A. 1995 Encountering Development. The Making and Unmaking of the Third World (Princeton, NJ: Princeton University Press).

Evans, P. 1995 Embedded Autonomy: States and Industrial Transformation (Princeton, NJ: Princeton University Press).

Ezquerro-Cañete, A. 2016 "Poisoned, dispossessed and excluded: a critique of the neoliberal soy regime in Paraguay" en Journal of Agrarian Change, 16 (4).

Filomeno, F. A. 2014 "Patterns of rule-making and intellectual property regimes: lessons from South American soybean agriculture" en Comparative Politics, 46 (4).

Foucault, M. 2001 Dits et écrits II (1976-1988) (París: Gallimard).

Gascón, J. y Montagut, X. (eds.) 2010 ¿Cambio de Rumbo en las Políticas Agrarias Latinoamericanas? Estado, Movimientos Sociales Campesinos y Soberanía Alimentaria (Barcelona: Icaria).

Giarracca, N. y Teubal, M. 2008 "Del desarrollo agroindustrial a la expansión del 'agronegocio': el caso argentino" en Mançano Fernandes, B. (org.) Campesinato e agronegócio na América Latina: a questão agraria atual (Buenos Aires / San Pablo: CLACSO / Expressão Popular).

Glassman J. 1999 "State Power Beyond the "Territorial Trap": the Internationalization of the State" en Political Geography, 18.

Grinberg, N. 2010 "Where is Latin America going? FTAA or "Twentyfirst-Century Socialism"' en Latin American Perspectives, 30 (1).

Grugel, J. y Riggirozzi, P. 2012 "Post-neoliberalism in Latin America: rebuilding and reclaiming the state after crisis" en Development and Change, 43 (1).

Gudynas, E. 2009 “Diez tesis urgentes sobre el nuevo extractivismo. Contextos y demandas bajo el progresismo sudamericano actual" en CAAP y CLAES (eds.) Extractivismo, política y sociedad (Quito: CAAP y CLAES).

Harvey, D. 2003 The New Imperialism (Oxford: Oxford University Press).

Harvey, D. 2006 "Comments on the commentaries" en Historical Materialism, 14 (4).

Henderson, T. P. 2016 "The class dynamics of food sovereignty in Mexico and Ecuador" en Journal of Agrarian Change, Early View, disponible en <doi:10.1111/joac.12156>. 
Jessop, B. 1990 State Theory. Putting the Capitalist State in its Place (Pennsylvania: The Pennsylvania University Press).

Jessop, B. 2007 "From micro-power to governmentality: Foucault's work on statehood, state formation, statecraft and state power" en Political Geography, 26 (1).

Karl, T. L. 1997 The Paradox of Plenty. Oil Booms and Petro-States (Berkeley: University of California Press).

Kay, C. 1974 "El sistema señorial europeo y la hacienda latinoamericana" en Historia y Sociedad, 1.

Kay, C. 1980 "The landlord road and the subordinate peasant road to capitalism in Latin America" en Etudes Rurales, 77.

Kay, C. 1998 "Latin America's agrarian reform: lights and shadows" en Land Reform, Settlement and Cooperatives, $\mathrm{N}^{\circ} 2$.

Kay, C. 2015 "The agrarian question and the neoliberal rural transformation in Latin America" en European Review of Latin American and Caribbean Studies, $\mathrm{N}^{\circ} 100$.

Lenin, V. I. 1950 (1899) El Desarrollo del Capitalismo en Rusia (Moscú: Ediciones en Lenguas Extranjeras).

Martínez-Torres, M. E. y Rosset, P. M. 2010 "La Vía Campesina: the birth and evolution of a transnational social movement" en Journal of Peasant Studies, 37 (1).

Marx, K. 1990 Capital. A Critique of Political Economy. Vol. I (Londres: Penguin).

Marx, K. 1991 Capital. A Critique of Political Economy. Vol. III (Londres: Penguin).

McKay, B.; Nehring, R. y Walsh-Dilley, M. 2014 "The "state" of food sovereignty in Latin America: political projects and alternative pathways in Venezuela, Ecuador and Bolivia" en Journal of Peasant Studies, 41 (6).

Minns, J. 2001 "Of Miracles and Models: The Rise and Decline of the Developmental State in South Korea" en Third World Quarterly, 22 (6).

Moore, J. 2010 "The End of the Road? Agricultural Revolutions in the Capitalist World-Ecology, 1450-2010" en Journal of Agrarian Change, 10 (3).

Ortiz, S.; Aparicio S. y Tadeo, N. 2013 "Dynamics of harvest subcontracting: the roles played by labour contractors" en Journal of Agrarian Change, 13 (4).

Otero, G. y Lapegna, P. (eds.) 2016 "Symposium: neoliberalism and transgenic crops in Latin America" en Journal of Agrarian Change, 16 (4). 
Panizza, F. 2009 Contemporary Latin America: Development and Democracy Beyond the Washington Consensus (Londres: Zed Books).

Perraton, J. 2005 "What's Left of "State Capacity"? The Developmental State after Globalization and the East Asian Crisis" en Harrison, G. (ed.) Global Encounters (Londres: Palgrave-MacMillan).

Petras, J. y Veltmeyer, H. 2003 "The peasantry and the state in Latin America: A troubled past, an uncertain future" en Journal of Peasant Studies, 29 (3-4).

Petras, J. y Veltmeyer, H. 2009 What's Left in Latin America? (Farnham: Ashgate).

Petras, J. y Veltmeyer, H. 2014 "Agro-extractivism: the agrarian question of the 21st century" en Petras, J. y Veltmeyer, H. (eds.) Extractive Imperialism in the Americas: Capitalism's New Frontier (Leiden: Brill).

Poulantzas, N. 1978 State, Power, Socialism (Londres: Verso).

Purcell, T. F. 2013 "The Political Economy of Social Reproduction Companies in Venezuela" en Latin American Perspectives, 40 (3).

Sader, E. 2011 The New Mole: Paths of the Latin American Left (Londres: Verso Books).

Selwyn, B. 2012 Workers, State and Development in Brazil. Powers of Labour, Chains of Value (Manchester: Manchester University Press).

Smith, N. 2006 "Nature as Accumulation Strategy" en Panitch, L. y Leys, C. (eds.) Socialist Register 2007: Coming to Terms with Nature (Londres: Merlin Press).

Urioste, M. y Kay, C. 2008 Latifundios, Avasallamientos y Autonomías: La Reforma Agraria Inconclusa en el Oriente (La Paz: Tierra).

Van der Ploeg, J. D. 2010 "The peasantries of the twenty-first century: the commoditisation debate revisited" en Journal of Peasant Studies, 37 (1).

Vergara-Camus, L. 2009 "The MST and the EZLN struggle for land: new forms of peasant rebellions" en Journal of Agrarian Change, 9 (3).

Vergara-Camus, L. 2013 "Rural social movements in Latin America: In the eye of the storm" en Journal of Agrarian Change, 13 (4).

Vergara-Camus, L. 2014 Land and Freedom. The MST, the Zapatistas and Peasant Alternatives to Neoliberalism (Londres: Zed Books).

Vergara-Camus, L. 2015 "Sugarcane Ethanol: the Hen of the Golden Eggs? Agrarian Capital and the State under Lula's Presidency" 
en Spronk, S. y Webber, J. R. (eds.) Crisis and Contradiction: Marxist Perspectives on Latin America in the Global Economy (Leiden: Brill).

Vergara-Camus, L. 2016 “Tomando el Control: Autonomía, subsistencia y de-mercantilización. Gérmenes de Otra Economía en las luchas de los Zapatistas en Chiapas y los Sin Tierra en Brasil" en Coraggio, J. L. (org.) Economía social y solidaria en movimiento / Quito: IAEN). Disponible en <http://editorial. iaen.edu.ec/wp-content/uploads/2016/06/Economia-Social-ySolidaria-en-movimiento-2.pdf $>$.

Watts, M. 2004 "Resource Curse? Governmentality, Oil and Power in the Niger Delta, Nigeria" en Geopolitics, 9 (1).

Webber, J. R. y Carr, B. (eds.) 2013 The New Latin American Left: Cracks in the Empire (Lanham, MA: Rowman \& Littlefield).

Weyland, K. 2009 “The Rise of Latin America's Two Lefts; Insights from the Rentier State Theory" en Comparative Politics, 41 (2).

Weyland, K.; Madrid R. L. y Hunter, W. (eds.) 2010 Leftist Governments in Latin America: Successes and Shortcomings (Cambridge: Cambridge University Press).

White, B.; Borras Jr., S. M.; Hall, R.; Scoones, I. y Wolford. W. (eds.) 2013 The New Enclosures: Critical Perspectives on Corporate Land Deals (Londres: Routledge).

Wissen, M. 2009 "Contested terrains: Politics of Scale, the National State and Struggles for the Control over Nature" en Review of International Political Economy, 16 (5).

Wolford, W.; Borras Jr., S. M.; Hall, R.; Scoones, I. y White, B. 2013 "Governing Global Land Deals: The Role of the State in the Rush for Land" en Development and Change, 44 (2).

Wood, E. M. 1995 Democracy Against Capitalism. Renewing Historical Materialism (Cambridge: Cambridge University Press).

Wood, E. M. 1999 The Origin of Capitalism (Nueva York: Monthly Review Press).

Wood, E. M. 2002 "The Question of Market Dependence" en Journal of Agrarian Change, 2 (1).

Wood, E. M. 2009 "Peasants and the market imperative. The origins of capitalism" en Akram-Lodhi, H. y Kay, C. (eds.) Peasants and Globalization. Political Economy, Rural Transformation, and the Agrarian Question (Londres: Routledge).

Zibechi, R. 2010 Dispersing Power. Social Movements as Anti-State Forces (Chico, CA: AK Press). 